\title{
LA UNIVERSIDAD ESPAÑOLA DEL 98 ANTE EL RETO DEL SIGLO XXI
}

\author{
Isabel Gutiérrez Zuloaga \\ Universidad Complutense de Madrid
}

\begin{abstract}
RESUMEN. Desde la perspectiva del año actual, 1998, se procura conectar con el amplio movimiento cultural y educativo que tiene lugar en el 1898 español, para proceder a reflexionar y reenfocar -en este 98 actual- el papel de nuestra Universidad en vistas al nuevo milenio.

Se recuerda la profunda preocupación educativa manifiesta en los escritos y discursos universitarios, en manifestaciones de instituciones culturales, en las publicaciones de la época. Así como se presentan algunos escritos sobre la "cuestión universitaria", en especial, en las obras de Miguel de Unamuno y de José Ortega y Gasset.

Se plantean cuestiones como las siguientes: ¿Tiene aún sentido la institución universitaria ante el duro reto de la postmodernidad? o ¿Cuál será el futuro de la formación universitaria?. Se defiende su papel como: promotora del saber, formadora de ciudadanos responsables, fomentadora del valor de la persona y de las relaciones personales. Se trata, pues de una "apasionante tarea" ante el futuro, como sector decisivo de la vida nacional, con gran capacidad para crear un intenso ambiente cultural, educativo, científico. Sólo así se podrá construir una Humanidad más fraternal, más defensora de los valores y derechos de todos y cada uno de sus ciudadanos.

DESCRIPTORES. Historia de la Educación Española - Generación del 98 - Política educativa - Unamuno - Ortega - Sentido de la Universidad - Universidad personalista Futuro de la Universidad
\end{abstract}

ABSTRACT. The wide cultural educative movement which took place in the Spanish 1898 is tried to be connected from the point of view of this present year, 1998, in order to think over and focus upon the role of our university in the new millenium.

It is remembered the educative concern standing out in texts and universitarian speeches given in cultural institutions and declarations and written in the newspapers at that time. Some works about the universitarian issue are also presentes, especially, those belonging to Miguel de Unamuno and José Ortega y Gasset.

Some questions are asked such as the following ones: Does the universitarian institution make any sense in postmodernity? or Which will the future of universitarian education be then? Its role is defended as: the promoter of knowledge, the educater of responsible citizens, the promoter of the person's worth and personal relationships. Therefore, it is an exciting job for the future, as a decisive sector in the national life, with great capacity to build up important cultural, educative scientific environment. This is the only way to have a humanity which is more fraternal and more defender of people's rights.

KEY WORDS. History of Spanish education, the 98 generation, Educative policy, Unamuno, Ortega, Sense of university, Personalizing University, The future of university.

1. Conferencia celebrada el día 26 de noviembre de 1998 en la Universidad de la Rioja como homenaje a Da Eulalia Martínez Medrano con motivo de su jubilación. 
Estamos finalizando el año 1998, centenario de aquella histórica fecha en la cual, tras el desastre colonial de 1898, surge en la sociedad española una profunda conciencia de crisis, de preocupación por la situación del país y de ansias de reforma, en todos los ámbitos de la vida. Este deseo de renovación se manifiesta, tanto en los grupos liberales como en los conservadores, en los intelectuales y tambien en parte de la juventud. A los escritores que adoptan esta actitud ideológica se les definirá, más tarde, como los hombres de la generación del 98.

Nos interesa el hecho de que surja una gran preocupación pedagógica, de que se produzca un claro despertar del interés por la reforma de la educación, hasta entonces desconocido. Interés pedagógico que se dejará sentir también en la Universidad, por lo que nos vamos a encontrar con que sus principales representantes salen con frecuencia a la palestra para defender un mejor funcionamiento del sistema educativo, así como una institución de educación superior más acorde con su propia Misión y más formadora de la personalidad y de la capacidad del español.

Analizaremos estas cuestiones del 98 pasado, para pasar a realizar una visión prospectiva -desde nuestro propio 98- de la labor educativa de la Universidad.

Los capítulos a tratar en esta temática van a ser: I.- Conciencia de crisis en la España de 1898.; II.- Propuestas para una nueva política educativa.-; III).- Se replantea la Misión de la Universidad; V).- Universidad de calidad y educadora para el nuevo siglo.

\section{Conciencia de crisis en la España de 1898}

El año 1898 simboliza el fin de un período de la cultura española y el comienzo de nuevos enfoques culturales. El desastre colonial estimula la conciencia crítica de un grupo de escritores que, sintiendo la necesidad de una urgente reforma de la sociedad española, clamará contra la situación moral, técnica, científica y pedagógica de España. Se produce un movimiento ideológico denominado regeneracionismo, en el convencimiento de que España sólo saldría de su deficitaria situación si se incorporaba a la mentalidad europea. Para lograrlo se van a propugnar reformas culturales. Lo que producirá un giro profundo en la historia del pensamiento y de la mentalidad de nuestro país y una honda revisión de todos sus valores.

El mismo Ortega escribe: "Regeneracionismo es el deseo. Europeísmo es el medio de satisfacerlo. Es decir, España es el problema, Europa la solución". Enfoque que, de ser un sincero testimonio del desencanto de una minoría intelectual, pasa a convertirse en el lema de una nueva clase social, la pequeña burguesía. Reflejo de la situación serán aquellos tan cantados versos : "Desde Cádiz a Gijón, -desde Lugo a Castellón, -toda España o casi toda, -después de la última poda, -grita ¡Regeneración!".

Se critican algunos falsos mitos patrióticos. Así, Lucas Mallada reconoce en 1890 en su obra Los males de la patria, muchos de los problemas reales, y ataca el absurdo concepto de la "riqueza natural" de España, para pasar a confesar que el suelo español es pobre, que la industria no prepara "herramientas, máquinas y material de ferrocarriles para librarnos del tributo al extranjero". Concluye haciendo una llamada al "impulso de conocimientos útiles en artes y ciencias...". 
En la misma línea está el escrito de Ricardo Macías Picavea sobre El problema nacional -de 1899- en el que declara: "Todo está echado a perder en este desdichado país: no hay gobierno, ni partidos, ni marina, ni ejército. Todo es ruina y decadencia". Para él, el pueblo español está atrofiado, el Parlamento debe ser cerrado por ineficaz. Y llega a enumerar hasta ventidós defectos nacionales, entre ellos: el caciquismo, el centralismo, el militarismo, la vagancia y la pobreza.

Otra preocupación del regeneracionismo es la de analizar el carácter español. Recordemos las obras de: Miguel de Unamuno, En torno al casticismo; Ramiro de Maeztu, Hacia otra España; Morote, La moral de la derrota; Azorín, El alma castellana; R. Altamira, Psicología del pueblo español; Joaquín Costa,... Estos escritores analizan, no la realidad externa o espectacular del país, sino su verdadera vida y su mentalidad, lo que Miguel de Unamuno va a calificar acertadamente de "intrahistoria".

Aún hoy, un siglo después, podemos reconocer que la Regeneración conserva toda su vigencia, ya que siguen latente entre nosotros dos ideas clave respecto a la solución de nuestros problemas: 1) la necesidad de una mejor y más eficaz educación de nuestro pueblo; 2) la urgencia de una total integración en Europa.

\section{Propuestas para una mejor política educativa}

Al reflexionar sobre los medios más eficaces para superar el lamentable estado en que se encuentra la nación, los pensadores ponen su vista en la Educación. Piensan que es ésta la panacea que ha de resolver la cuestión española, la verdadera tabla de salvación ante los retos que debe asumir nuestro país, y se reclama para ella una atención prioritaria. El gran interés que despierta la educación da lugar a que los temas pedagógicos sean estudiados con profusión.

En este sentido Ivonne Turin, en su artículo titulado precisamente así: "1898. El Desastre ¿Fué una Ilamada a la educación?", presenta como evidente el que "1898 clausura un siglo en el que la instrucción y la educación han hecho su entrada en el campo de la política oficial...". También D. Gómez Molleda nos hablará del "pedagogismo del 98".

\section{Los escritos de los intelectuales}

Los intelectuales del momento, pedagogos o no, se interesan por la educación y se proponen analizar los problemas reales que sobre ella se plantean. Aunque, hemos de reconocer, que este movimiento paneducacional está protagonizado -muy en especial- por los miembros de la Institución Libre de Enseñanza, los cuales no cesan de defender las exigencias formativas de la sociedad española desde todos los medios a su alcance, como son: cátedras, conferencias, publicaciones... Y los nombres que más se destacan en este cometido de diagnosticar las deficiencias de la educación serán: F. Giner de los Ríos, M. B. Cossío, G. Azcárate, R. Altamira, P. de Alcántara, M. García del Real, Rafael Ma ${ }^{a}$ Labra, Adolfo Posada, Concepción Saiz, Aniceto Sela,...

Así, M. B. Cossío expone, en la Asamblea Nacional de Productores de Zaragoza, lo que él considera como las reformas más urgentes en el campo de la educación. Son varias y exigen soluciones diversas. Entre ellas: 1)- Formar al personal de enseñanza, lo que supone reforma de programas, métodos,...; 2)- Dedicar más presupuesto a la 
enseñanza y emplearlo mejor; 3)- Aumentar el número de centros escolares; 4)Ampliar la enseñanza obligatoria hasta los 13 años; 5)- Reorganizar las escuelas rurales; 6)- Fomentar las escuelas de adultos... De dichas exigencias, considera que, unas corresponde resolverlas al Estado, otras al profesorado, otras a los estudiantes, otras a las familias, y otras a toda la sociedad.

El Catedrático de la Universidad de Oviedo, Rafael Altamira, resume los problemas de la educación nacional en "disminuir el número de analfabetos mediante la difusión y la solidez de la enseñanza primaria". Piensa que para ello se requiere, sobre todo, tres elementos: 1)- dinero para edificios; 2)- dinero para pagar a los maestros; 3)personal preparado para enseñar. Pero de los tres, coloca este tercero como primordial porque, si esto falla "todos los gastos serán inútiles y el mejor programa será un fracaso. Y como ese personal nos falta, la cuestión fundamental para nosotros debe ser la formación de Maestros, la reforma de las Escuelas Normales, que a su vez necesitan de profesores inspirados en el espíritu pedagógico moderno... pero estos profesores también nos faltan". Además, Altamira llega a constituir una sociedad, la Aproximación franco-española, con el fin de establecer relaciones culturales y educativas con el país vecino. De ella van a formar parte varios personajes del momento, entre ellos, el pintor Ignacio Zuloaga.

Por su parte, P. de Alcántara García escribe lamentando el descuido en que se tiene a la enseñanza básica: "La historia contemporánea no ofrece ejemplo de pueblo alguno que, habiéndose encontrado en las circunstancias en que se ha encontrado España, después de los terribles desastres y de las enseñanzas del luctuoso año 1898, haya mirado con tan grande indiferencia, y tratado con tanta falta de tino y tan menguado criterio, los asuntos de la educación elemental".

Es de destacar el Informe previo presentado por Rafael María Labra en la votación de los presupuestos del Estado, donde expone cómo en España el 67\% de los ciudadanos son analfabetos, por lo que la instrucción primaria debe ser una gran preocupación al preparar dichos presupuestos. "Sin duda alguna -escribe- tienen mucha importancia la enseñanza secundaria y los problemas de la enseñanza superior y universitaria, en relación con el presupuesto del Estado. Pero, por nuestro retraso y por la situación excepcional de España en estos últimos años (principalmente a partir de 1898) la enseñanza primaria es realmente el problema pedagógico de nuestro país,... La enseñanza primaria es fundamento de la sociedad, el supuesto necesario de la vida común contemporánea, la condición primera de la moderna vida política..."

Así se manifiesta Adolfo Posada cuando en 1901 escribe en el BILE: "...si hacemos abstracción de la pura agitación política, si damos de lado a una multitud de manifestaciones superficiales, que responden más o menos fielmente a crisis reales y positivas de la conciencia nacional, se puede afirmar que el movimiento interno más interesante... que se ha producido en España durante los últimos años, ha sido el movimiento de la reflexión sobre la situación actual y sobre los medios más idóneos para levantarse de la caída ocasionada por los terribles desastres de España". Y pasa a quejarse con amargura de la rutina y el estancamiento en que ha caído la educación: "El problema de nuestra educación es cosa muy grave...". Aunque vé como positivo el que este convencimiento ha dejado de ser exclusivo de minorías, puesto que son cada vez más los ecos que se hacen oir alertando sobre el tema. Posada reconoce que se 
ha producido un movimiento de preocupación pedagógica porque "preocupa el asunto", dado que "se mueven y discuten las cuestiones pedagógicas y el grave problema de la educación nacional en el Parlamento, en la prensa, en reuniones especiales,..."

Aniceto Sela, catedrático de Derecho de la Universidad de Oviedo, describe los problemas o necesidades siguientes: 1)- Formación de Maestros y retribución de los mismos; 2)- Locales para centros escolares, dotados de condiciones higiénicas; 3)Ayuda a las familias para que envíen sus hijos a la escuela; 4)- Educación postescolar; 5)- Colonias escolares de vacaciones... Aunque está convencido de que la educación, aun concebida integralmente, no es omnipotente, y la responsabilidad de la misma no recae sólo sobre la escuela primaria. Aniceto Sela escribe sobre la responsabilidad de toda la sociedad, que "a todos nos interesan los problemas de la ciencia y el arte de la educación".

También Matilde García del Real enumera los problemas que debe solucionar el Estado español al comienzo del siglo, que son: 1)- La transformación de las escuelas primarias; 2)- La educación de la mujer; 3)- La educación del adulto. Aunque piensa que los tres pueden reducirse a uno: la educación permanente del ciudadano.

\section{Discursos universitarios sobre Educación}

Vamos a fijarnos en algunos de los Discursos pronunciados al finalizar el pasado siglo en la Inauguración del Curso universitario. Porque resulta sumamente significativo el hecho de que personas pertenecientes a ambientes muy diversos y desde muy diferentes perspectivas científicas y profesionales, eligieran como tema para sus discursos de apertura de curso de las diversas Universidades la problemática educativa.

Así, en la Universidad de Valencia, en el Discurso leído en la apertura del curso académico 1898-1899, por P.M. López Martínez -Catedrático de Metafísica- afirma que "El exámen de la naturaleza humana nos enseña que el porvenir será de aquellos pueblos que sepan unir al vigor del sentimiento por sus ideales, el mayor grado de educación e instrucción de sus individuos".

En la Universidad de Barcelona, en el Discurso leído en la apertura del curso académico 1899-1900, por E. Mascareñas Hernández, Catedrático de la Facultad de Ciencias, tras analizar el estado de la enseñanza en general, se ocupa de la situación de la enseñanza de las Ciencias experimentales.

Por su parte, en la Universidad de Madrid, pronuncia el Discurso de apertura de curso de 1900-1901 el entonces Ministro de Instrucción Pública, A. García Alix, en el que informa sobre las perspectivas de actuación de su Ministerio.

Y en la misma fecha, M. Candela Plá - Catedrático de Medicina - pronuncia en la Universidad de Valencia el Discurso cuyo título es ya altamente significativo: "Rehabilitación social de España basada fundamentalmente en la educación del pueblo".

\section{Los universitarios ante las instituciones culturales}

Se pronuncian Discursos en el Parlamento. Así R.M. de Labra, trata, ya en 1898 en el Congreso de los Diputados, sobre El problema político-pedagógico de España, haciendo referencia a los problemas básicos de la educación nacional. Dos años más 
tarde, habla en el Senado, al tratar del presupuesto de Educación pública para 1902, sobre Los Maestros, la Educación Popular y el Estado.

También son de destacar las intervenciones de A. Sardá en el Senado; tanto en el discurso de 1903, en la preparación del Presupuesto de Instrucción Pública, que diserta sobre de La Primera Enseñanza en el Senado; como en la interpelación que en 1904- dirige al Ministro de Instrucción Pública sobre la creación de escuelas.

Se escuchan conferencias en Asambleas, Congresos, Jornadas. Así, A. Manjón defiende los Derechos de los padres de familia en la educación e instrucción de sus hijos en el Congreso Católico de Santiago de 1902. En la Asamblea Universitaria de Valencia -1902- habla, en nombre de la Universidad de Madrid el catedrático I. Calvo Madroño acerca de las Condiciones jurídicas de la libertad de enseñanza.

Son también dignos de tenerse en cuenta los Discursos de Ingreso en las Reales Academias. En especial, el de F. Olóriz, en la Real Academia de Medicina, en 1900, que tiene por objeto El analfabetismo en España. O el de J.R. Carracido, que en su discurso de ingreso en la Real Academia de Ciencias, elije como tema: la Educación científica que deben tener los españoles para cumplir los más elevados fines del progreso, en el orden material, moral y social, realizando con ellos las aspiraciones humanas.

Entre los discursos pronunciados en el Ateneo de Madrid, tenemos -en 1902- los de L. Alvarez Morote, La educación social en la vida contemporánea y de E. Bullón Fernández, El clasicismo y el utilitarismo en la enseñanza.

\section{Surgen publicaciones periódicas}

Se fundan además, en este período de entre siglos, numerosas revistas y periódicos especializados en la temática educativa en varias provincias españolas. Vamos a recordar algunas:

- Ya en 1899 comienza a imprimirse, en la ciudad de Logroño, el Boletín de la Asociación del Magisterio Público Riojano; y en Madrid, El Criterio.

- Al año siguiente se publican: en Barcelona, un Boletín pedagógico español; en Valencia, El Campeón del Magisterio; y en León, El Magisterio de León.

- En 1901 aparecen: el Boletín escolar, órgano del profesorado de Durango, en Vizcaya; La Enseñanza Moderna en Lugo; y La instrucción, órgano independiente de la enseñanza, en Guadalajara.

\section{Se replantea la misión de la Universidad}

En esta etapa se va a plantear el problema universitario como un problema estratégico para la sociedad, al considerar la perspectiva pedagógica de esta institución de enseñanza superior. Ello da lugar a que destacados universitarios y líderes del pensamiento español, dediquen abundantes páginas de sus obras a reflexionar y a exponer su punto de vista sobre lo que denominan la misión educadora de dicha Institución, como son: Francisco Giner de los Ríos, Santiago Ramón y Cajal, Manuel García Morente, Miguel de Unamuno, José Ortega y Gasset. 


\section{Diversos enfoques del "problema universitario"}

El gran universitario y buen profesor que fue Francisco Giner de los Ríos plantea el concepto de Universidad, que no es para él "una idea absoluta que pueda especulativamente construirse; un factor eterno, indispensable, de la vida social, sino un concepto histórico. Sólo apelando a la historia cabe, pues, definirlo. Y, al igual que toda entidad histórica, no es sino una forma peculiar de cumplirse en ciertas sociedades tal o cual función permanente que, como todas, admite soluciones muy distintas según la condición de los tiempos".

Lamenta que en la Universidad española se trasmita la ciencia hecha, es decir, lo investigado y trabajado por otros, estudiando y asimilando el texto favorito... y renunciando a toda convicción personal. Y es que piensa que el estudiante no va a la escuela ni a la Universidad "a discutir, a preguntar,... a despertar gérmenes de su personalidad física, intelectual, moral, afectiva, a educarse, en suma, en cuerpo y en alma, sino sólo a instruirse... y a aprender lo que oyen".

Por su parte confiesa que "Tengo mi cátedra, procuro en ella no sólo enseñar la materia que me está encomendada, sino disciplinar y avivar la mente de mis alumnos, obrar sobre cada uno de ellos, hacer obra pedagógica". Sobre el alumnado nos conunica su profundo deseo de: "Hacer un universitario distinto, que se caracterice por el rigor de su preparación científica y profesional, por su integridad moral, por su desinterés hacia los medios fáciles y brillantes...".

El catedrático de la Universidad Central, Santiago Ramon y Cajal, reconoce que debe a la Universidad lo que sabe y lo que vale, y considera que su situación va mejorando: "Afortunadamente -escribe- la Universidad española de hoy siente ya ansias de vida y renovación y desea caminar resueltamente por la vía del progreso. Revélase en algunos de sus maestros... loable emulación por sacudir la tutela intelectual extranjera, por cooperar con propio y personal esfuerzo a la conquista pacífica de la naturaleza y el arte..., por fortuna nuestras aulas (fortalezas de autoridad y rutinarias) se han abierto al espíritu crítico..., trabajemos porque la Universidad sea lo que debe ser: tanto fábrica de ideas como foco de educación y cultura nacionales". Mientras que considera que él, como profesor, tiene nuy en cuenta la metodología científica y didáctica, y se preocupa por dar a su enseñanza un enfoque práctico y experimental.

Por su parte, Manuel Garcia Morente se lamentaba de que la Universidad había degenerado "en ligereza" y la sabiduría "en pedantismo". Defiende que no se puede imponer la autonomía, sino que se deben crear los medios para irla adquiriendo: "La autonomía universitaria es hoy un ideal; no puede ser una realidad mañana, dentro de cuatro meses, sólo porque así lo exija la Gaceta". Aunque quiere dejar bien claro que "muchos profesores deseamos la autonomía universitaria. Pero la deseamos en el corazón, y no en el papel; la deseamos conquistándola y no recibiéndola".

\section{La enseñanza universitaria según Miguel de Unamuno}

El Rector de la Universidad de Salamanca, Miguel de Unamuno, dedicó muchas páginas a analizar la cruda realidad de la Universidad española. Su análisis crítico acierta a teñirlo de una sutil ironía, al tiempo que procura aportar soluciones factibles de llevar a la práctica. En su escrito De la enseñanza superior en España (1899) se pregunta: “¿Claustro? ¿Corporación? De esto no hay nada ni puede haberlo. Lo impide la 
organización misma de nuestra Universidad, y lo impide, sobre todo, el feroz individualismo que nos caracteriza y el espíritu de dogmatismo intransigente y sectario... Hay blancos y negros que luchan a alfilerazos, y pardos y grises que van viviendo y cobrando. $\mathrm{Y}$ un sin fin de filisteos, porque nuestra Universidad es madriguera de ellos". Y añade: "El libro mata la cátedra o ésta se convierte en lo que Ilaman los alemanes un seminario; en un laboratorio y centro de investigaciones, y no de retórica. Y el laboratorio cabe en todo, en todo aquéllo en que quepa labor"

Piensa que la Universidad española -a principios del siglo XX- no existe como corporación, como institución comunitaria, sino sólo como un mecanismo; y si crece, es más bien, por yuxtaposición que por su propio dinamismo interior. Se lamenta, además, de que viva de espaldas a la sociedad española y a la europea.

En La enseñanza universitaria. ponencia que presenta a la II Asamblea universitaria se queja de que las Facultades universitarias son "meros depósitos docentes de ciencia ya hecha", "mostradores en que se expende" la lección, "en vez de ser talleres de ideas, en vez de ser fecundos laboratorios" . Se convierten así en "fábricas de abogados, médicos, farmaceúticos o catedráticos". O, aún peor, porque se reducen a actuar como "oficinas del Estado para la administración de la enseñanza pública superior".

Clama por una renovación intelectual, puesta al servicio del bien de la sociedad, tal como escribe: "La patria misma es una tradición, una tradición ineludible, y la Universidad debe ser su principal factor de progreso. Unos cuantos sabios, verdaderos sabios, maestros de verdad, guardan más a la patria que algunos batallones".

He aquí la meta que señala para la Universidad: "Aquí hay que hacer la unidad honda, la espiritual, la comunión más bien. Mientras no comulguemos en un ideal lo bastante amplio para que en él quepamos todos los españoles, no habrá patria española. La vieja resulta ya un poco estrecha; hay que ensancharla, pero ensancharla por dentro y en espíritu y en verdad. Alma de tolerancia; mente hospitalaria; culto a la verdad, sintiéndola viva, proteica y multiforme; comprensión a las más opuestas concepciones, abierta; odio al formalismo; atención al pueblo; heroísmo de trabajo; sumersión en la realidad concreta, fija la vista en la más alta idealidad abstracta..." Y concluye: "Si no nos da todo esto la Universidad, habrá que darle garrote vil y aventar luego sus cenizas". Pero además nos va a exponer modelos concretos de actuación en diversos campos: "Las cátedras de literatura podían organizar la cosecha de cantares y cuentos y consejos populares, en vez de contar la biografía de Calderón; las de Economía, llevar a cabo trabajos como los de Mr. Le Play y su escuela, recoger la vida económica ambiente; las de Derecho, impulsar la obra ingente que ha emprendido don Joaquín Costa, la de recoger el derecho consuetudinario; las de Geología, Botánica, Zoología, etc... harto tienen con nuestro suelo, y flora y fauna... Hay que descubrir España a los españoles; sólo así podrá haber lo que Ilamamos ciencia española, que mejor sería decir ciencia en España".

En la citada Asamblea propone, además, que el Gobierno patrocine y subvencione las publicaciones científicas del profesorado universitario, para que se divulguen, y que los profesores lleguen a ser "algo así como el estado mayor del ejército de los publicistas".

Además, don Miguel, fue un auténtico maestro de la juventud universitaria. Tiene siempre presente a los jóvenes, tanto en sus conferencias, como en sus discursos, artí- 
culos, ensayos, cartas, y en la comunicación de cada día. Él mismo comenta a su amigo Mújica: "Se me ha acusado de que busco a los jóvenes que quieren trabajar, me pongo en relación con ellos, les animo y escribo largas cartas". Pero es verdad que dirigía su mirada esperanzada al alumnado: "Es en los jóvenes -les dice en el Discurso de Apertura del curso 1900-1901, de la Universidad de Salamanca- en quienes ha de poner la patria sus esperanzas más corroboradoras ... A vosotros los jóvenes toca disipar la plúmbea nube de desaliento que a tantos cela la ruta del porvenir. Sois vosotros los que tenéis que descubrirnos a España y marcarla luego un fin, que no lo es ella misma".

El Rector de Salamanca lanza su lema para cada uno, que es Estudio y vida. Porque está convencido de que la renovación no se puede hacer desde arriba sino desde abajo. De arriba vienen decretos, intentos, pero la verdadera reforma de la enseñanza universitaria ha de venir de los propios estudiantes.

\section{Caracteres de la Universidad, según Ortega}

Ortega destaca dos conceptos claves cuando habla de la Universidad: su carácter intelectual y su carácter eminentemente europeo. Para él "La Universidad es el intelecto" y "Europa es la inteligencia", porque el hombre europeo decidió preferir y anteponer la inteligencia a todas las cosas del universo. es una institución esencialmente europea, occidental: "la universidad, el cultivo y la enseñanza del saber organizados como corporación pública, como institución, es algo exclusivamente europeo". Y sigue: "la universidad ha sido consustancial con Europa". Ha significado un principio diferente del Estado, aparte, cuando no enfrente. Ha sido el saber constituído como poder social: "la magia de la universidad se alzó como genuino, exclusivo y auténtico poder espiritual".

Lo que es evidente es que la pedagogía orteguiana universitaria da primacía a los valores intelectuales, a la trasmisión del saber y a la cultura. Está convencido de que la juventud necesita que se le ofrezcan valores positivos, que deben ser ideas sólidas. Así recrimina a un profesor escéptico: “¿con qué derecho no cree $\mathrm{Vd}$. que se puede hacer algo por España?... Que un hombre inteligente y perspicaz como $\mathrm{Vd}$... alce la voz y ofrezca lo que las generaciones jóvenes...necesitan sin saberlo. Dénsele ideas sólidas y se verá cómo cambia el escenario".

Después Ortega va a reseñar los caracteres que considera imprescindibles para el adecuado funcionamiento de esta secular institución. Recordemos algunos: - La Universidad no puede convertirse en provinciana, ni siquiera en nacional, ya que la cultura y el saber que imparte no tiene fronteras, debe ser universal; - La Universidad no puede enfocarse de modo utilitario ni pragmático, ni reducirse a responder a las necesidades inmediatas de la vida o a preparar para una profesión, sino que debe ser, ante todo, un foco de cultura, una búsqueda creadora del saber, que forme a las personas e irradie en su ambiente; - La Universidad no puede anclarse en una pedagogía anticuada, con desconocimiento de los progresos realizados en este sentido, sino que debe potenciar el cultivo de las ciencias de la educación, racionalizar el aprendizaje y renovar la metodología educativa; - La Universidad no puede ser un aparcamiento de masas ni un centro colectivizante, sino que debe regular la admisión de sus alum- 
nos. Sólo así podrá obtener una formación individualizada preparándolos para que sean un prometedor fermento de promoción de la sociedad.

Insistirá también sobre la necesidad de ofrecer a los jóvenes valores intelectuales y morales profundos y duraderos, así escribe: "A los veinte años es preciso encontrarse frente a uno, mejor, varios sistemas intelectuales lo suficientemente firmes para satisfacer las menudas exigencias de verdad que a esa edad se tienen... El que a los veinte años no ha creído en un sistema moral, y no se ha estrechado y comprimido en una jerarquía, es el resto de sus días un ser vago y funambulesco, que será incapaz de poner tres ideas en raya o en fila". Porque Ortega piensa que cuando hay hondura intelectual hay drama, hay vida profunda, ya que la inteligencia capta la propia realidad vital. Esta hondura es la que hay que trasmitir a la juventud.

\section{Universidad de calidad y educadora para el nuevo milenio}

Comenzábamos reconociendo nuestra actual inmersión en un nuevo curso, centenario de aquél en que un grupo de hombres comprometidos, en una mezcla de enojo y de esperanza, dedicaron tanto esfuerzo y levantaron tantas espectativas para la renovación de nuestra sociedad. También hoy, nuevos e importantes retos condicionan el futuro: un nuevo siglo, cambios económicos y sociales, nuevo enfoque del mercado de trabajo, avances tecnológicos, la integración en la Unión Europea, ... Es evidente por tanto- que la enseñanza universitaria debe experimentar una profunda transformación, empujada por los cambios de la propia sociedad.

Ante todo, la nueva sociedad será una sociedad cognitiva; se basará en el conocimiento, en un desarrollo intelectual que capacite para el pluralismo, la iniciativa y la creatividad. Lo que exige una adaptación continuada y una revisión permanente y una puesta a punto de nuevas metodologías. Estamos, por tanto, obligados a hacer una proyección responsable hacia el siglo que viene, proyección que ha de ser realmente decisiva para la Universidad española.

De momento, empezaremos por formular la cuestión radical: ¿ Tiene aún sentido la institución universitaria ante el fuerte reto de la postmodernidad?. Cuestión que plantea Carmine Romanzi, Presidente de la Conferencia de Rectores Europeos, en las Jornadas organizadas en 1988, con motivo del Centenario de la fundación de la Universidad de Deusto (Bilbao). Este Rector, en la conferencia inaugural de la sección sobre Universidad y Sociedad, se cuestiona si tiene sentido actualmente la Universidad.

Veamos su respuesta: la Universidad es una institución predominantemente educativa ¿qué se quiere decir con ésto? Pues que debe impregnar de hálito cultural a las nuevas generaciones. Pero, ¿qué es para él la cultura? Tras ir desgranando los elementos que comprende el concepto de cultura, considera que ésta significa el "equilibrio y la armonía de las distintas facultades del espíritu humano", así como "la correspondencia del saber con la honestidad y con la sabiduría del sentir y del querer, con la ética que regula el ejercicio de la libertad y de la justicia, y con la práctica de toda virtud que exalte a la persona humana". Cultura es también -según él"todo aquello que permite al hombre indagar en el propio espíritu y en el de los demás, orientarse en el propio tiempo" y hacia el "futuro", y "saber moverse en el pro- 
pio espacio". Después de tan bello análisis Ilega a decir: "Hablar de cultura es también y -sobre todo- hablar de Universidad", pero además va a añadir: "El problema de la cultura es eminentemente europeo".

Por lo tanto, sólo fomentando la vida cultural, será como esta institución puede "contribuir a la elevación del nivel intelectual, moral, profesional y social del ciudadano". Y la cultura se adquiere mediante la docencia y la investigación. Concluye afirmando que, si la Universidad cumple "con todos estos requisitos" y sigue siendo un baluarte y centro de libertad al servicio de la verdad, es y será siempre plenamente necesaria. Por tanto, no cabe duda de que puede "reivindicar su espacio propio en el mundo contemporáneo".

\section{1) ¿Cuál será el futuro de la formación universitaria?}

Hemos de reconocer que, muchas de las ideas de Giner de los Ríos, de Miguel de Unamuno, de Ortega y Gasset, sobre todo en lo relativo a los métodos pedagógicos y a la función de la educación, son notablemente actuales y además válidas para enfocar el futuro.

La Universidad debe ser, ante todo, una institución promotora del saber. A través del cultivo del saber promueve lo más hondamente humano y se convierte en una intensa fuerza revolucionaria para mejorar al hombre y a la sociedad. Este es también el enfoque de Hutchins: "La Universidad se funda en el supuesto de que, en alguna parte del Estado, debe existir una organización cuyo propósito sea meditar sobre los problemas intelectuales más importantes. Su finalidad es iluminar todo el sistema educativo y las cuestiones teóricas y prácticas que se plantean a los pensadores especulativs y a los hombres de acción". Sobre todo, Hutchins considera como esencial a la actividad universitaria la formación de buenos ciudadanos, por lo que añade: "La finalidad del sistema educativo en su conjunto, no es proveer de obreros a la industria o enseñar a los jóvenes a ganarse la vida. Es formar ciudadanos responsables".

Postulamos, además, que la Universidad debe ser personalista, que debe fomentar por todos los medios el valor de la persona y de las relaciones interpersonales; debe evocar y reivindicar la libertad y la dignidad del hombre, de todo hombre; y debe ser vínculo de unión entre los hombres. Con este sentido, Resweber define a la institución universitaria como "signo de disciplinariedad" y nos dice: "La Universidad debe ser símbolo de unión, porque es un privilegiado espacio de encuentro de investigadores, profesores y estudiantes... La relación profesor-alumno es, en realidad, una aventura donde aquél que de antemano "sabe", corre el riesgo de "no saber", es decir, de que su conocimiento sea juzgado a través de su calidad expresiva, del calor de su comunicación y del valor de su significado". Y es que Resweber concede una gran fuerza formativa a la comunicación, y defiende que: "el saber no tiene otro destino que el ser compartido y, como consecuencia, romperse durante el acto comunicativo, estallar, para convertirse en palabra".

Pasemos a analizar las soluciones propuestas en vistas a este futuro próximo, por alguna de las entidades universitarias supranacionales. Así, vamos a recordar el Encuentro que celebró en Munich la Asociación Internacional de Universidades 1983- , cuyo objetivo fue El futuro de la Universidad: hacia la generalización o la 
especialización. En él se plantearon tres cuestiones concretas: 1) Las formaciones que conducen a los diplomas de los primeros ciclos; 2) Las formaciones de tercer ciclo y la investigación; 3) Los nuevos campos de la educación permanente y el reciclaje.

Hemos de aceptar que, en casi todos los Encuentros actuales, se muestra como objetivo clave la calidad de la enseñanza universitaria. Era ya tema preferido en nuestro intelectuales del 98 y, en la actualidad y a nivel internacional, sigue despertando sumo interés. Por lo que la evaluación de la Universidad parece que resulta hoy imprescindible. En España, tenemos reciente la convocatoria en el B.O.E. del segundo año del Plan de Evaluación de la Calidad de las Universidades. Evaluación que puede servir, tanto para poner en marcha nuevos proyectos, como para orientar la financiación, comprobar la validez de algunas titulaciones, estimular innovaciones pedagógicas, ...

Aunque creo es preciso tener muy en cuenta que, para una auténtica valoración de esa calidad, no basta con el simple análisis de la función docente, sino que es preciso atender a todos y cada uno de los elementos que hemos ido analizando a lo largo de esta exposición, ya que todos ellos se integran e influyen en el funcionamiento de la nuestra Institución.

Una serie de acciones concretas para la formación universitaria del futuro se sugieren en el Libro Blanco de la Comisión Europea publicado en 1995, y titulado Enseñar y aprender: hacia la sociedad cognitiva. Recojemos algunas:

1) Equilibrio entre la adquisición de conocimientos y el perfeccionamiento en la capacidad metodológica, lo que suponne no sólo saber cosas, sino saber hacer cosas;

2) Incremento de la actividad de adquirir nuevos conocimientos o, dicho de otra forma, elevación del nivel general de conocimientos, mediante la creación de redes mundiales de investigación y formación;

3) Integración de la vida académica con la profesional y social; acercamiento entre la universidad y la empresa, establecimiento de prácticas en empresas;

4) Desarrollo de las aptitudes sociales: comportamiento en la vida social y laboral, capacidad de cooperación y decisión, creatividad,...;

5) Dominio de las lenguas, sobre todo europeas;

6) Formación más práctica, con períodos de estudios menos largos.

Esta claro que, la demanda social de formación que hoy se plantea a la Universidad no se limita sólo a la actualización de la oferta educativa sino que, además, tiene que ampliarse a aspectos innovadores o previsores de la evolución futura.

Para superar nuestra actual situación se precisa mejorar, entre otros elementos importantes, sobre todo: 1) la calidad; 2) la eficiencia en la gestión universitaria; 3) la coordinación.

\section{La Universidad, "apasionante tarea" ante el futuro}

¿Seguimos pensando que existe el "problema universitario"? o ¿podemos asegurar -con J. Pagés- que lo que denominamos problema es más bien un buena oportunidad para ayudar a mejorar su eficacia intitucional?. Según él, en su artículo "La 
Universidad )problema u oportunidad?" nos dice "Más que un problema es una oportunidad. La oportunidad de incrementar nuestra competitividad, de acelerar el proceso social, cultural y económico y empujar el avance de una sociedad que, cada día más, requerirá del conocimiento para hacer realidad sus aspiraciones.

Reconocemos que, en este final de siglo, la Universidad ha cambiado en muchos aspectos, pero no cabe duda de que la actual sociedad española reclama de ella mucho más que en el pasado. Nuestra institución es hoy objetivo de muy variados ámbitos sociales, los cuales solicitan una mayor y mejor formación, así como una respuesta eficaz a sus exigencias personales y profesionales.

Estamos plenamente convencidos de que la Universidad es un sector decisivo en la vida nacional. De aquí que ésta no pueda, en modo alguno, eludir su gran responsabilidad social. Es preciso modificar contenidos y estrategias para satisfacer esta demanda social, estas expectativas de los ciudadanos, de que se actualice la oferta académica universitaria, expectativas que debemos esforzarnos en reconocer y en lograr que sean plenamente colmadas. Aunque, claro está, que un sistema no evoluciona si no se le somete a desafíos y tensiones internas. Se precisa crear un tenso nivel de ejercicio de la responsabilidad en todos los universitarios: profesores, alumnos, gestores,... Se ha dicho que el rasgo característico de la Universidad es su capacidad para educar. Crear un intenso ambiente educativo, cultural, científico. Desarrollar un pensamiento y una investigación independiente y crítica. Porque debe desarrollarse en ella una crítica constructiva de todas las pretensiones y aspiraciones sociales.

Se hace preciso, además, el colaborar en la formación de la conciencia europea. Hay que diseñar, experimentar y validar nuevas estrategias educativas capaces de lograr mejoras significativas de la calidad de la enseñanza. Hemos de propiciar una cultura pedagógica que nos permita la integración más total en Europa.

Por tanto, debemos conseguir la mejora de la calidad de nuestras instituciones educativas. Tenemos que defender la trascendente misión social y elevadora de la Universidad, para alcanzar en el Tercer Milenio una sociedad más humana, es decir, más comprensiva, más tolerante, más equitativa, más solidaria, más constructiva, más pacífica,... y una Humanidad más fraternal, más defensora de los valores y derechos de todos y cada uno de los ciudadanos.

Este es el reto. ¿Estamos dispuestos a aceptarlo y a dedicar toda nuestra capacidad y nuestro esfuerzo en alcanzar la meta?. Pues, si es así, vamos a concluir recogiendo el mensaje del genial Unamuno, quien al cerrar uno de sus lúcidos artículos, dirige tres palabras al ciudadano español, sólo tres palabras, que son: "Y ahora, !A trabajar todos!".

\section{Referencias Bibliográficas}

ALCÁNTARA GARCÍA, P. de(1900): "Estado de la educación al empezar 1900". La Escuela Moderna, 106; p. 4.

ALTAMIRA CREVEA, R.(1898): "El patriotismo y la Universidad". B.I.L.E., XXII; pp. 257-270, 291-296, 323-327.

CAMPUS, P.(1986): Reconstruire I'Université. París: Abatros. 
CASTILLEJO DUARTE, J.(1906): "Pedagogía universitaria". B.I L.E., XXX; pp. 70-75. COMITÉ NACIONAL DE EVALUACIÓN.(1987): Oú va I'Université?. París: Gallimard. COMUNIDADES EUROPEAS (1995): Enseñar y aprender: hacia la sociedad cognitiva. Documento COM (95). Bruselas: Comisión de las —.

CONSEJO (1995c): Programa de evaluación inicial de la calidad de las Universidades. Madrid: — de Universidades.

CONSEJO (1996h): Una década en la Universidad española. (datos y cifras). Madrid: — de Universidades.

GUTIÉRREZ ZULOAGA, I.(1962): "Responsabilidad social de la Universidad". Eidos, 17 ; pp. 244-247.

GUTIÉRREZ ZULOAGA, I. y CANES GARRIDO, F.(1985): La Primera Asamblea universitaria española. 1902. Higher education and society historical perspectives. Salamanca: Universidad, II; pp. 75-89.

GUTIÉRREZ ZULOAGA, I.(Ed.) (1986): Homenaje a José Ortega y Gasset (1883-1983). Madrid: Universidad Complutense.

GUTIÉRREZ ZULOAGA, I.(1987): El programa pedagógico de Giner de los Ríos. Un educador para un pueblo. Madrid: U.N.E.D.; pp. 91-109.

GUTIÉRREZ ZULOAGA, I.(1988): "Manuel García Morente en la Universidad de Madrid". Cuadernos de Pensamiento, 2; pp.43-58.

GUTIÉRREZ ZULOAGA, I.(1991): La Universidad en el momento actual. Avila: Tellamar; pp. 345-354.

LENA, P.(1994): "Les universités craquent". Le Monde de l'Education, 219; pp. 44.

LUXAN, J.M.de(Ed.)(1998): Política y reforma universitaria. Barcelona: Cedecs.

MASSIT-FOLLÉA, F. y EPINETTE, F.(1992): “L'Europe des Universités. L'enseignement supérieur en mutation". Les études de la Documentation Française.

MICHAVILA, F. y CALVO, B.(1998): Reflexiones sobre la Universidad española. Madrid: Síntesis.

MIGUEL, M. de y otros(1991): La evaluación de las instituciones universitarias. Madrid: Consejo de Universidades.

NEAVE, G.(1996): "L'Enseignement Supérieur en transition...". Gestion de l'enseignement supérieur, 8; p. 3.

OCDE (1987): Las Universidades bajo escrutinio. París.

ORTEGA Y GASSET, J.(1931): "La misión de la Universidad". B.I.L.E., LV; pp. 84-91, 109-117, 143-147.

POSADA, A.(1910): "La transformación del ideal universitario". B.I.L.E., XXXIV; pp. 321-329.

QUINTANILLA, M.A.(1996): "Nuevas ideas para la Universidad". La Universidad del siglo XXI y su impacto social. Las Palmas de Gran Canaria: Universidad; pp. 35-48.

SCHWARTZ, L.(1983): Pour sauver I'université. París: Seuil. 
ROMANZI, C.(1988): "Universidad y Sociedad". Universidad y Sociedad. Bilbao: Universidad de Deusto.

SELA, A.(1893): "La misión moral de la Universidad". B.I.L.E., XVII; pp. 5-11, 23-27, 53-56, 71-76, 90-91, 103-109.

SELA, A.(1904): "Fin y organización de las Universidades". B.I.L.E., XXVIII; pp. 230234.

SELA, A.(1905): "La Segunda Asamblea universitaria". B.I.L.E., XXIX; pp. 68-76.

TEZENAS, H.(1985): L'Université peut mieux faire. París: Seuil.

UNAMUNO, M.de(1966): La enseñanza universitaria. Obras Completas. Madrid: Escelicer, t. IX.

UNESCO (1995): Documento de política para el cambio y el desarrollo de la Educación Superior.

ZOLLER, C.(1994): "Le défi de I'internationalisation de I'enseignement supérieur...". Gestion de l'enseignement supérieur, 6, 1; pp. 43-51. 